\title{
Power Sector Decarbonization in South Asia Pathways for Research, Modeling, and Implementation
}

\author{
A Product of the South Asia Group for Energy
}

\section{Power Sector Decarbonization}

Decarbonization of the power sector has far-reaching impacts in terms of the further decarbonization of the economy. In many comprehensive decarbonization pathways proposed for the world and for India, electrification of transportation, buildings, and industry is the principal solution to decarbonizing those sectors (Chaturvedi and Malyan 2021; Davis et al. 2018).' Therefore, electricity grids are likely to grow as more and new loads are added to them, and this growth will necessarily be from non-carbon-emitting resources. This report outlines several key challenges for the power sector in planning, research, and development toward a decarbonized electric power grid. While these challenges will continue to evolve, this report focuses on formulating important questions for the next two decades to align planning timeframes of India's and South Asia's power sector stakeholders, and to offer near-term research solutions for preparing the data sets, building the models, and designing the studies to answer questions and prepare for these changes.

\section{Near-Term Pathways}

India's power sector has changed substantially in the past several years as it sought to meet its target of $175 \mathrm{GW}$ of renewable energy by 2022. The successes toward this goal have been enabled by regulatory initiatives, studies of technical and economic matters, enhancements in power system flexibility in the form of markets and ancillary services, and upgraded operating practices, among other developments (Soonee et al., n.d. 2017). A recent policy target of $500 \mathrm{GW}$ of renewable energy by 2030 is now shaping the power sector transformation, and the longer-term ambition of India reaching a decarbonized economy by 2070 (Modi 2021) will shape the big questions that need to be answered in the coming decades. ${ }^{2}$

According to the Central Electricity Authority (CEA), India's power generation in Fiscal Year 2020 was 11\% from renewable energy (CEA 2021). ${ }^{3}$ CEA plans project that these sources will reach about $31 \%$ of the generation by 2029-30 (CEA 2020).

In addition to reaching policy targets, development trends of wind and solar point toward these technologies as being the defining transformation of the power sector in the next several decades. Solar energy (in the form of photovoltaics) has grown at a rate of about $85 \%$ from 2015-2020 (IEA 2021; 2016). Wind has also grown substantially, increasing from 13 GW in 2010 to over 43 GW in 2020 (IEA 2021). Power system development trends across the globe are headed in the same direction, with global renewable energy capacity projected to rise over $60 \%$ between 2020 and 2026 (IEA 2021).

These technologies require a shift in planning for and operating the power system. Some of these shifts have already started to occur in India: (1) renewable energy forecasting by developers and system operators is widespread; (2) CEA has recently started to consider multiple time scales in planning to account for variability in wind and solar (CEA 2020); and (3) thermal plants are now mandated to turn down to $55 \%$ of nameplate capacity (CEA 2019c) to help accommodate variability largely brought on by a need for more system flexibility, among many other changes happening in markets and regulatory environments (Economic Times 2021). Many of these changes are meant to inform and increase the flexibility of the power system. These practices will continue to evolve as renewable energy continues to grow and represent a larger portion of the generation in the country.

In addition to system-wide evolution, technologies such as energy storage in the form of batteries will necessitate innovation to planning and operating processes. Several studies have identified India as a potentially large market for energy storage (Chernyakhovskiy et al. 2021; Abhyankar, Deorah, and Phadke 2021), and some local systems have started to emerge (Tata Power 2021). However, several questions about the optimal use of these systems, the value that they provide, and their interdependence on renewable energy, remain. It is likely that as developers, planners, and operators get familiar with these technologies, more studies will be required to understand the extent and potential of their impact.

\footnotetext{
1 Electrification is used throughout this paper to indicate technologies using electricity as the source of energy or as the act of switching from another energy source, such as direct fuel use, to electricity. 
In addition to trends in renewable energy and storage growth, decarbonization of nonpower sectors (industry, transportation, buildings) has the potential to radically alter the total growth of the power system due in large part to the new loads on the system (Davis et al. 2018). If, for example, industrial electrification needs were to be met by the bulk grid, the requirements for generation would be very large and have both broad system impacts and acute local impacts. And given the trends in generation growth, it is likely that renewable energy would be the cost-competitive choice to meet all or at least a very large portion of the energy. Transportation and building electrification would further these needs. These decarbonization impacts would be on top of an already difficult demand prediction (Spencer and Awasthy 2019; Spencer 2020).

The following sections outline some of the key questions, data needs, and subsequent studies that will help to understand the challenges and identify solutions for decarbonizing the power sector. This report is meant to fill a gap in what is a very active conversation on decarbonization pathways in the region by focusing on the research and development studies and analysis that could be undertaken in the near- to mid-term. This report is one of a three-part series on decarbonization by the South Asia Group for Energy (SAGE).

\section{High Renewable Energy Grids Are Required for Decarbonization}

As indicated by trends in generation growth and policy targets, India and other South Asian countries grids are likely to continue transitioning to high levels of renewable energy, which is likely a requirement for the larger economies of the region to decarbonize. ${ }^{4}$ Therefore, a good understanding of the technologies and their impact on the grid will be critical. A substantial amount of research has already been performed to help understand the grid of the future, both in India, South Asia, and globally. Studies such as Palchak et al. (2017), McBennett et al. (2019), Rose et al. (2018) helped in understanding the challenges that may be faced in operating India's grid with 175 GW of renewable energy. Additional work on cross-border electricity trade in the region helped clarify how India's renewable energy ambitions would impact regional opportunities (McBennett et al. 2019; Joshi, Hurlbut, and Palchak 2020). And several studies of the next phase of policy targets for 2030 have shed light on what additional planning and operational challenges may be faced in the coming years (CEA 2018; Abhyankar, Deorah, and Phadke 2021; Rose et al. 2020; Chernyakhovskiy et al. 2021).

However, many questions remain about how the grid should be planned, operated, invested in, resilient to a changing environment and landscape of technological advancements, and kept reliable. At national renewable energy penetrations over 30\%, a lack of detailed or extensive power system studies exist on how these resources will be integrated into India's or neighboring countries' grids. India has several states to look to for clues about high penetrations of renewable energy in the country, such as Karnataka and Gujarat, but a lot is yet to be learned. And the electrification of the economy further accelerates the need to look forward and make sure that current practices are on the right path. Studies looking at these higher levels can be beneficial for many reasons: (1) in some cases, these studies can uncover additional foundational research that needs to be undertaken, starting as soon as possible, such as investments in next-generation technologies or reengineering of entrenched processes that may take years to change; (2) they can inform the private sector of longer-term opportunities, which can spur innovation; and (3) policies across sectors can be aligned so that electrification pathways do not have unintended consequences (e.g., electrifying transport while the grid is still fossil-based may have unexpected emissions impacts).

The following sections detail data, tools, and study objectives for the foundation of a decarbonized economy: a low-carbon grid powered largely by wind and solar energy.

\section{No-Regrets Data \\ Synchronous Electricity Demand and Weather Data}

Weather data that is synchronized with electricity demand (historical) will be critical to ascertain the resource adequacy of future power systems and to understand the potential challenges in operation. The value of these correlated data sets is a common refrain from power system planners and researchers around the globe and forms the primary inputs for the European Network of Transmission System Operators for Electricity's (ENTSO-E) planning methods (Redefining Resource Adequacy Task Force 2021; ENTSO-E 2020). Having many years of correlated data has the potential to open the door to innovative power sector studies that will lead to greater resource adequacy, resilience, and reliability. In addition to serving the needs of traditional power system studies, the synchronized data will be critical for deeper dives into high renewable energy futures and deep electrification of transport, industry, and buildings.

As wind and solar become larger parts of the generation mix and load diversifies, understanding the generation on many time scales will be important, and simple assumptions about wind and solar generation, such as scaling up existing profiles or ignoring spatial variability (for generation or transmission needs), will be

4 Other technologies could play a significant role in the coming decades; however, the transition to wind and solar will likely be the defining trend in the transition to clean energy. 


\section{Electricity Demand Data Can Open Doors to New Questions}

Electricity demand data is a vital part of planning the power sector and is often inaccessible publicly in the format, spatial granularity, or time scales required to model technological shifts, such as from electrification. The Electric Power Survey created by CEA forms the basis of forecasting demand for India and has utilized both end-use methodology (bottom-up) methods throughout the years and recently undertook additional econometric modeling to reinforce and compare forecasts (CEA 2019a; 2017; 2019b). However, while these forecasts can help form the basis of power sector models, additional detail is likely required for studies that attempt to capture temporal variability, such as hourly balancing challenges, or spatial detail, such as transmission network power flows. Bottom-up models, such as the National Renewable Energy Laboratory's (NREL's) demand-side grid (dsgrid) model developed for the United States, helps to fill the gap in demand data for power system studies in the United States (Hale et al. 2018). Dsgrid aggregates several physics-based models of residential, commercial, industrial, and transport sectors to be suitable for power systems analysis. ${ }^{5}$ It is likely that many of these resources exist in siloed and unsynchronized fashion in India and other South Asian countries, but further research, development, and aggregation could produce these models and data sets in a public domain so that power sector stakeholders can easily integrate the resources into detailed power sector studies. The availability of dsgrid data enabled several large-scale studies, such as the Electrification Futures Study (Mai et al. 2018) and Los Angeles 100\% Renewable Energy Study (Hale et al. 2021). inadequate to study the ability of renewable energy to meet the diversifying demand profile. And decarbonization of the power sector will be a huge shiftlikely over decades - and the unknown variables are multiple. But creating high-resolution weather data and increasing the utilization of it in all planning time scales will help to decrease uncertainty. As an example, one primary consideration for decisions that have decadal impact is ensuring that there are enough resources to serve load under all potential circumstances (i.e., resource adequacy). This requires multiyear data sets to look at many different types of potential weather events - both probable and tail events. Just as there are sometimes years of drought, there may be certain events, for example, where wind speeds or solar irradiance is lower than normal for extended periods of time. A recent NREL study examined the impact of extreme weather on power system operations, identifying several events that may benefit from a deeper understanding by system operators (Novacheck et al. 2021). Several key findings suggest that renewable energy does not markedly change the reliability during extreme events, such as cold or heat waves. However, one key finding is that there may be weather-related events that are currently not considered noteworthy (mild weather conditions), that produce extended periods of low wind or solar resource, and that deserve greater attention in a future with high levels of renewable energy generation. Understanding the interrelatedness of various weather impacts to the power system will only grow with more wind and solar generation and load diversification.

\section{Pathways for High Renewable Energy Grid Development}

NREL's study on energy storage in South Asia explored several potential future grids, one being a future grid with a constraint to build no new coal- and gas-fired capacity past 2023 (Chernyakhovskiy et al. 2021). ${ }^{6}$ While this is not current policy or meant to indicate that this is an optimal policy, it is indicative of what the system needs are if the grid were to be powered exclusively by zero-carbon sources.

In this scenario, the 2050 grid has no fossil-fueled generation capacity. Instead, the grid is powered mostly by solar and wind energy, with substantial growth in 10-hour storage beyond other scenarios in the study. A notable departure from other scenarios, where fossil-based plants were built after 2023, is that the wind development was substantially more, reaching 1,600 GW by 2050, more than double any other scenario. There was also $50 \mathrm{GW}$ of new nuclear and $18 \mathrm{GW}$ of biomass capacity by 2050. Pumped hydro also saw substantially more growth than most other scenarios. These results indicate that capacity is the largest driver for new infrastructure in a high renewable energy grid. Greater amounts of wind combined with 10-, 8-, and 6-hour battery storage are prime contributors to the reliable capacity (Figure $\mathbf{1}$ ).

While the No New Fossil scenario of growth to 2050 provides many indicators about possible development pathways, it leaves out a great deal of potentially disruptive new advancements or operational changes. One is the potential for demand to play a greater role in balancing the grid, which could, among other things, offset the need for some capacity that is used infrequently throughout the year. Lawrence Berkely National Laboratory explored the potential for agricultural loads to shift at a 10-times greater

\footnotetext{
5 The physics-based models of dsgrid, such as ResStock ${ }^{\mathrm{TM}}$ (residential buildings), use methodologies that are specific to each sector and are utilized in studies outside of the power sector to understand the impacts around, for example, energy efficiency policies (https://www.nrel.gov/analysis/dsgrid.html).

6 The scenarios in this study were designed to explore the role of energy storage in South Asia in the future. However, scenarios from this study can be used to indicate trends and possible development pathways for the whole power system. Follow-on studies could delve further into specific options for a decarbonized grid, for example, by including next-generation technologies or varying other infrastructure cost parameters that have the potential to be targets for policies.

7 The need for capacity is distinct from the need for energy. Much of the wind and solar energy produced in the No New Fossil scenario is curtailed, but to meet the highest demand periods of the year, and have reserve in case of contingencies, more capacity is built.
} 


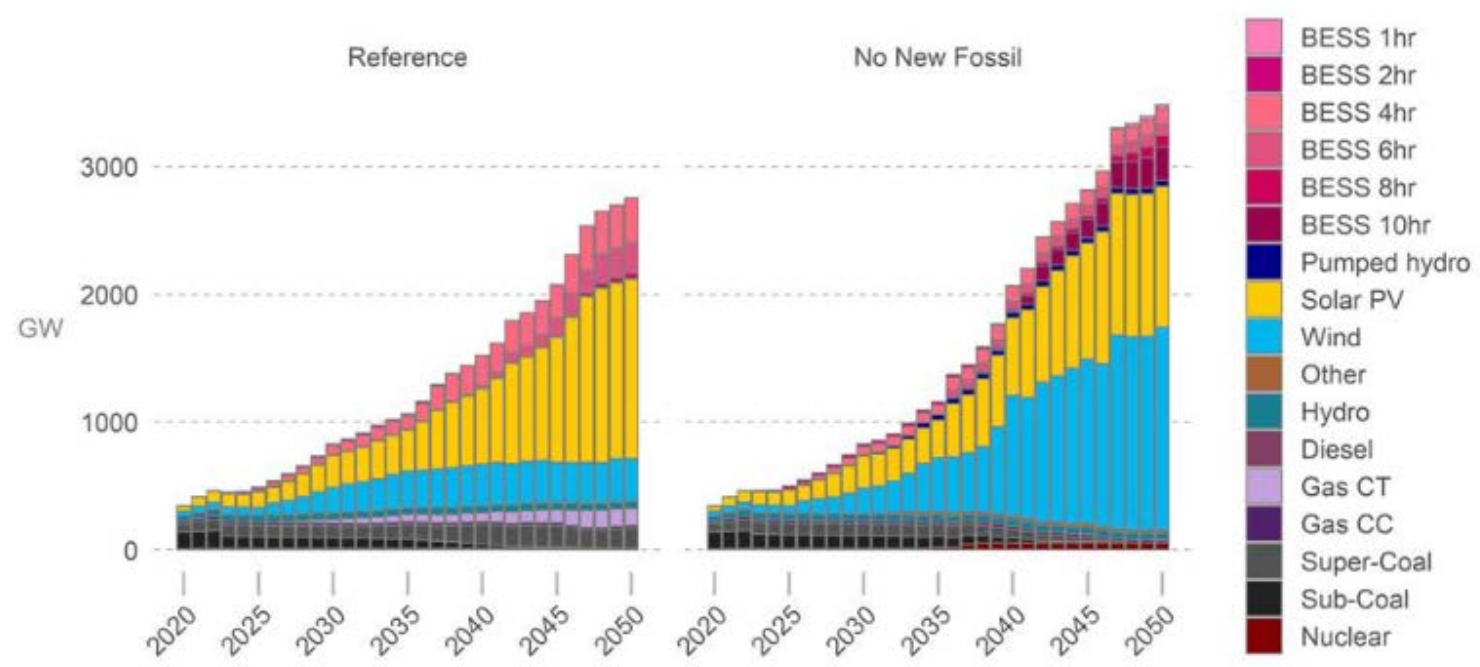

Figure 1: Installed capacity from 2020-2050 in Reference and No New Fossil scenarios. BESS stands for battery energy storage systems. Source: (Chernyakhovskiy et al. 2021)

capacity than is done today to explore the value of this resource (Abhyankar, Deorah, and Phadke 2021). While this study looked only to 2030 , it still indicates that a large agricultural demand response program could have a substantial impact on the amount of capacity that needs to be built in India.

In addition to agricultural load, the electrification of other sectors has the potential to offer opportunities for load shifting, which could help to ease the generation and storage capacity requirements for future decades. ${ }^{8}$ For example, many studies envision using an electrified transport fleet to help balance the grid (Anwar et al. 2022). And industrial processes, while potentially limited in their direct electrification potential, could still benefit from coordination with the grid. For example, hydrogen production requires large amounts of energy and is seen by many as critical to meeting economy-wide decarbonization goals. If these production facilities rely on the grid (through electrolysis), it is feasible that production would decrease in certain periods and increase in others to take advantage of lower electricity prices
(Biswas, Yadav, and Baskar 2020; Eichman, Harrison, and Peters 2014; Guerra et al. 2019). Integrating these potential large loads, and their potential for providing grid services, into power sector planning could help to define the short- and longterm needs locally (on distribution and transmission systems), and even change the equation for central- or South Asia regional-level planning. ${ }^{9}$ In high renewable energy grids, the ability to examine in necessary detail the time-varying components of load shifting and renewable energy generation will be a principal challenge, and will likely have large impacts on the generation capacity and transmission infrastructure that results.

\section{New Frontiers in Power System Studies: 100\% Renewable Energy Grids}

The past decade of power system studies have demonstrated that cost-effective and reliable power system operation is fully achievable with very high shares (50\%-80\%) of variable renewable energy in the generation mix (Bloom et al. 2021; Brinkman et al. 2021; Mai et al. 2018). And, based on real-world experience from places like Denmark, California, South Australia, and Ireland, and from extensive research, many solutions for large-scale renewable energy integration are largely known (Denholm et al. 2021). However, deep decarbonization of the power system in South Asia may entail policymakers and system planners considering scenarios approaching 100\% renewable energy. NREL's groundbreaking study for the city of Los Angeles provided important insights about the challenges and potential solutions for 100\% renewable energy power systems (Cochran, Denholm, and eds 2021). A key insight is that pathways diverge for the last 10\%, which poses both economic and technical challenges. From the economic perspective, building additional renewable energy to meet the last 10\% of energy demand will be more expensive (with today's technology) due to the declining marginal value of wind and solar resources (Figure 2). As the renewable energy requirement approaches 100\%, the marginal cost of $\mathrm{CO}_{2}$ abatement rises nonlinearly to over 10 times the abatement cost at $80 \%$ renewable energy. This is largely due to the mismatch, both

8 Demand-side management is already used widely in many places in the world and India (BEE 2020). Although the scale is far lower than envisioned in most electrification-based projections.

9 Model linkages between sectors has the potential to pass information both ways, from electrifying sectors to the grid planners, and back to sectors to signal economic development opportunities. Examples of directly linking infrastructure requirements between hydrogen production and electricity planning exemplified the impact to system infrastructure requirements (He et al. 2021). 


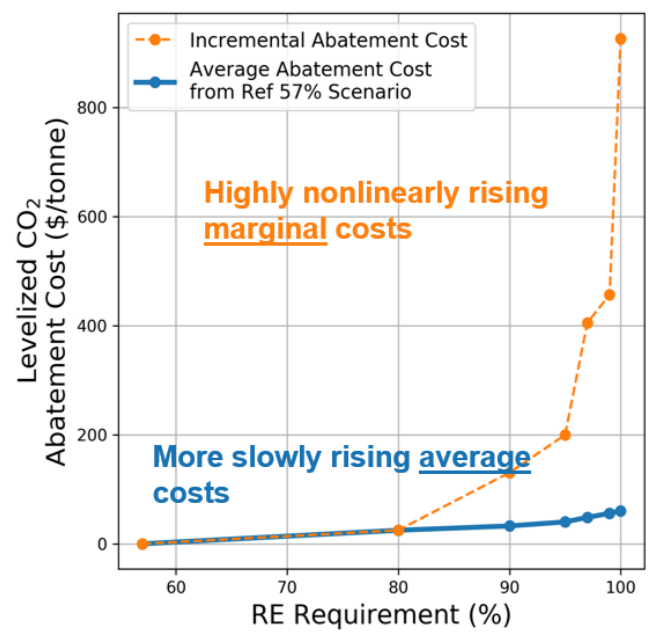

Figure 2: Costs of achieving a 100\% renewable energy electricity grid.

Source: (W. J. Cole et al. 2021)

diurnal and seasonal, of supply from variable renewable energy and patterns of demand. Several alternative solutions have been proposed, including biomass, hydrogen fuel cells, hydrogen combustion turbines, multiday demand response, and negative emissions technologies like biomass with carbon capture and storage, although the commercial viability of these alternatives is not yet fully understood.

Achieving 100\% renewable energy systems also presents technical challenges that require new research and development initiatives. Maintaining frequency stability with inverter-based resources, system protection, control interactions, and needed capabilities of grid-forming inverters are all ongoing research and development efforts. In India and across countries in South Asia, studies can begin to assess the resource mix and technology developments that would enable a deeply decarbonized power system. Initial studies can identify key areas where additional country-specific efforts are needed.

As demonstrated in the Los Angeles study, assessing pathways for 100\% renewable energy also benefited from representing the interaction of the electricity grids with transportation and buildings sectors, distribution networks, and the distributed resources at the grid edge. And capturing the benefits of power system transformation requires applying novel methods to assess the full range of air quality and environmental justice impacts. When combined, these studies can provide a more complete picture of $100 \%$ renewable energy transitions in South Asia. For example, Figure $\mathbf{3}$ shows the interdependence of models and data flows used for the Los Angeles $100 \%$ study.

\section{Electrification: Broadening the View of Grid Planners}

The rapidly changing generation mix in South Asia is a significant shift for power sector stakeholders. Utilities are having to adjust to new approaches in planning their generation, and development agencies are creating mechanisms for new power purchasing options (Prasad 2020; Bose and Sarkar 2019). However, the other side of the equation, the demand, is also likely to see rapid changes in the coming decades. There are already significant shifts happening in load types, such as from the growth in air conditioners and energy-efficient appliances that are causing changes to demand profiles (Abhyankar et al. 2017). And India's recent target announcement of being decarbonized by 2070 (BBC News 2021) is likely to accelerate some sectors to shift to electricity, possibly making the planning process even more complex for utilities and other stakeholders in the future.

The research needed to understand the potential for, and impact of, electrification is vast. For example, understanding the adoption of end-use technologies (e.g., electric vehicles, new building loads) could span technical, economic, and behavioral topics reaching far outside of typical power sector purviews. ${ }^{10}$

Regardless of the challenges in projecting electrification, studies can be undertaken by power sector researchers and key stakeholders that will help to frame the potential scale of impact to the grid and explore opportunities for the integration of previously loosely connected sectors. For example, NREL's Electrification Futures Study, which focused on the U.S. energy

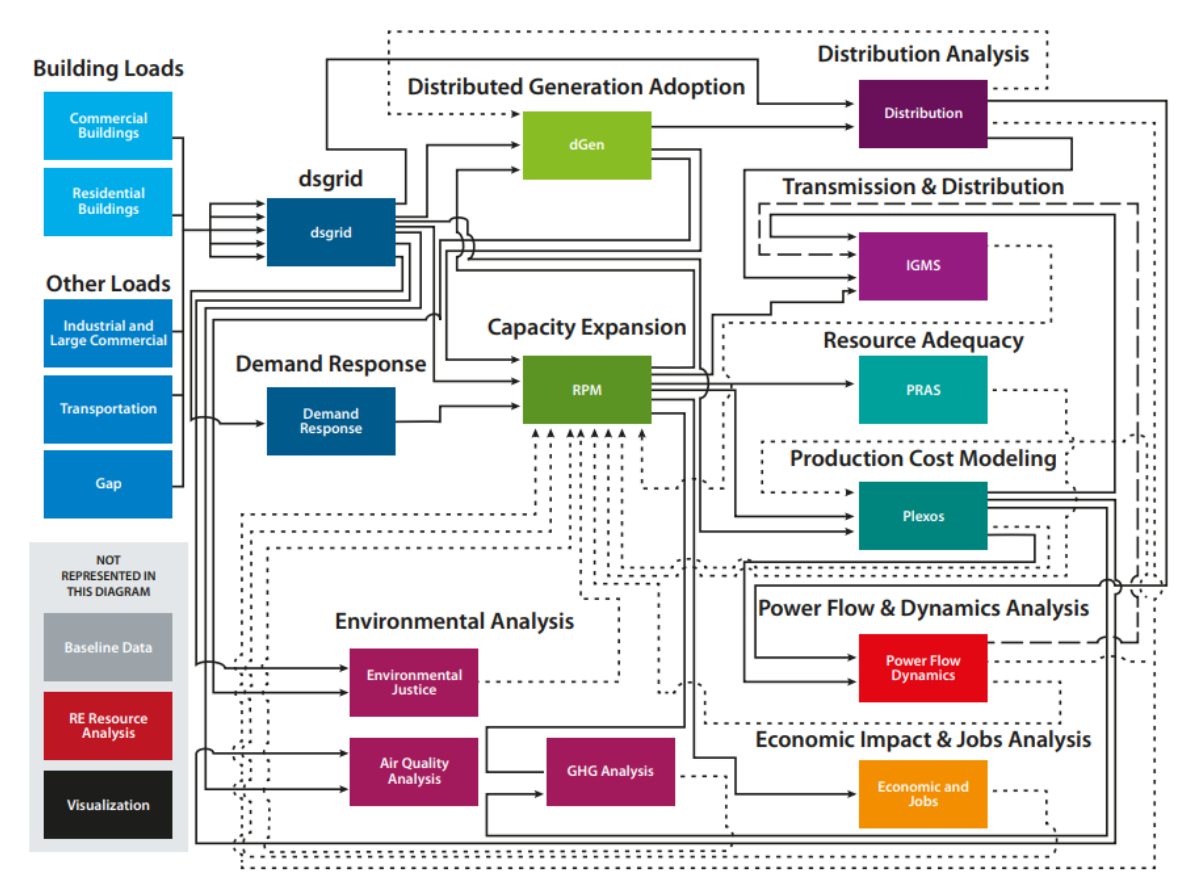

Figure 3: Study data flow for the Los Angeles 100\% study. Solid lines represent data flow, dashed lines represent feedback to inform modeling Source: (Cochran, Denholm, and eds 2021). 


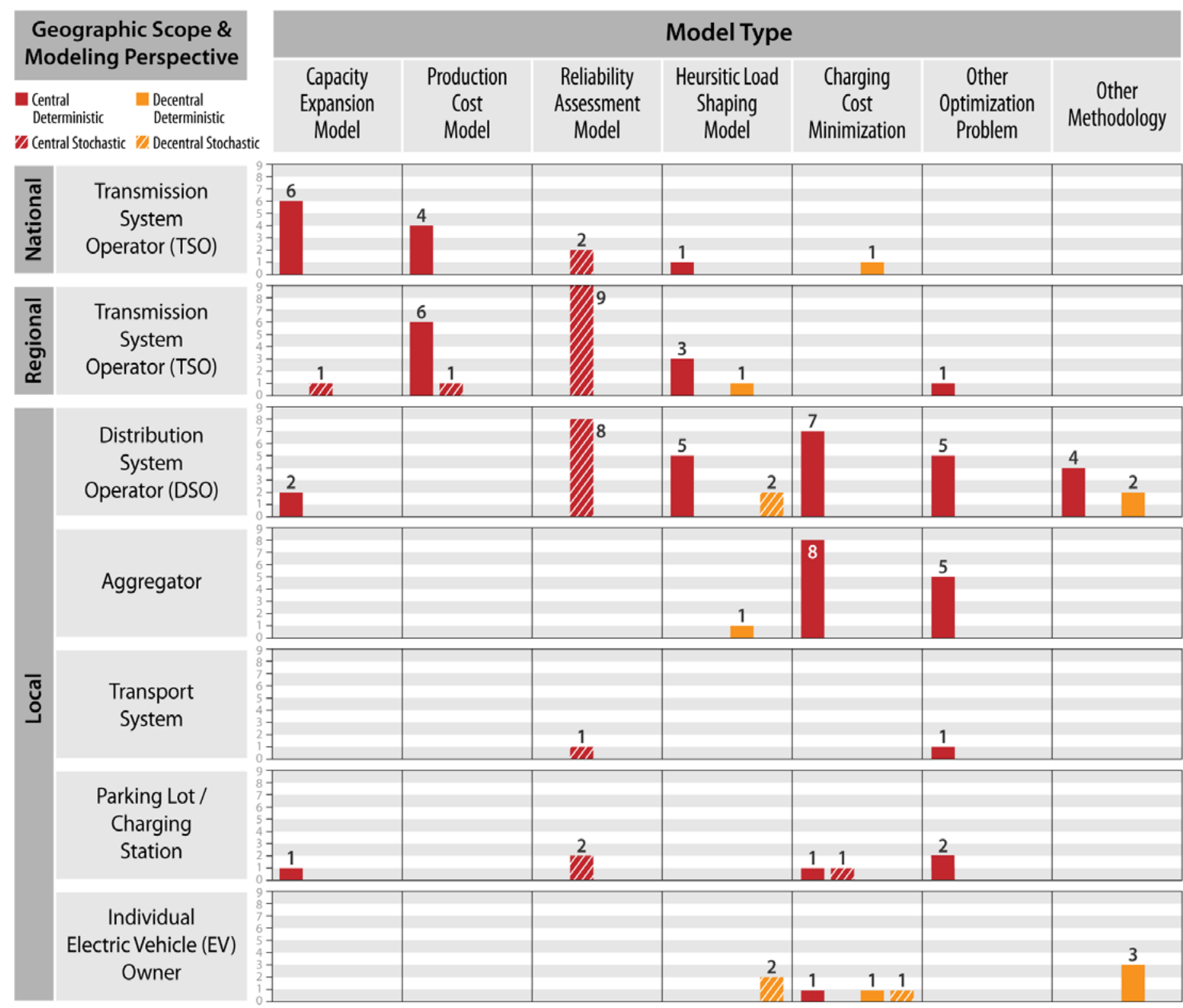

Figure 4: This plot summarizes the reviewed modeling/analysis studies by geographic scope, modeling perspective, model type, and methodology. The numbers represent the number of papers reviewed within that topic and scope. Source: (Anwar et al. 2022)

system, took a broad view of the impacts of several potential electrification scenarios to understand the supply-side needs (i.e., generation, storage, and transmission) and the operational impacts, finding that total energy demand could be as high as 38\% greater and peak demand as high as 33\% greater in 2050, depending on the degree of electrification (Mai et al. 2018).

An example of a narrower focus electrification question, although with broad applicability and extensively researched, is how to manage the charging of a growing electric vehicle fleet. A literature review of this topic Anwar et al. (2022) shows the extent to which this question can be framed, spanning multiple control strategies, several potential grid services from electric vehicles, communications and controls considerations, power flow deviations, cost and benefit analyses, reliability impacts, etc. Figure $\mathbf{4}$ shows the various studies, methods, and modeling perspectives represented by the set of studies considered, exemplifying that this somewhat narrow focus-how to manage charging of a vehicle-has broad impacts that will need to be understood by many in the power sector.
In India and the South Asia region more broadly, planning for large increases in load from new sectors may benefit from increased transparency and interlinked planning processes with other agencies to understand the temporal characteristics of future loads. Distribution utilities will be a critical link in helping to understand how all these pieces come together, but planning for electrification could be greatly improved by city agencies, state energy departments, and regional and central power system agencies coordinating on the expected impacts. 
Integrating High Renewable Energy Planning With Electrification Potential Will Benefit From Innovative Grid Planning

One of the primary challenges in planning in today's rapidly transforming power sector is that every aspect of the system seems to be on course for huge shifts. While demand in South Asia has been growing rapidly in recent years, the supply side of the equation was more familiar with decades of experience planning thermal-and/or hydro-dominated systems (i.e., generation and transmission options were well-understood using mostly established technologies). Now, demand has the potential to evolve significantly in the coming decades, and the generation resource mix is well underway for a complete transformation.

While the task of forecasting both a transforming generation mix and evolving demand when so many factors are uncertain is challenging, there are straightforward studies and methods that will need to be undertaken in the coming years to confidently transform the sector. Many of the questions that arise out of the topic of decarbonization are just accelerations or "high-ambition" scenarios from previous studies and are ready to be analyzed in greater detail, with whole studies built around what was previously considered extreme cases. On other more ambitious questions, research may need to support several years of data development and model building before robust analysis is available. The following sections summarize several studies and technical activities that have considered relevant questions for economy-wide decarbonization, although most were not performed with very high renewable energy grids or widespread electrification in mind, but rather helping to build frameworks that could be used by India's stakeholders to confidently transform their grids. In many cases, these studies are informative for technical insights and policy matters, but they also help to frame the next set of questions to be answered and data sets and models to build.

\section{Distribution Utilities}

Evolving Portfolios

Private or state-owned distribution utilities (DISCOMs) in India and the region have a critical role to play in planning for the transforming power sector. In many respects, they are at the center of many of the questions that require further exploration-forecasting customer loads, procuring power, and managing a growing behind-the-meter sector (i.e., distributed energy resources such as rooftop solar, batteries, and demand response). NREL has worked with several utilities in India to understand both sides of the equation. From the supply side, there is clear interest in understanding better how renewable energy will integrate

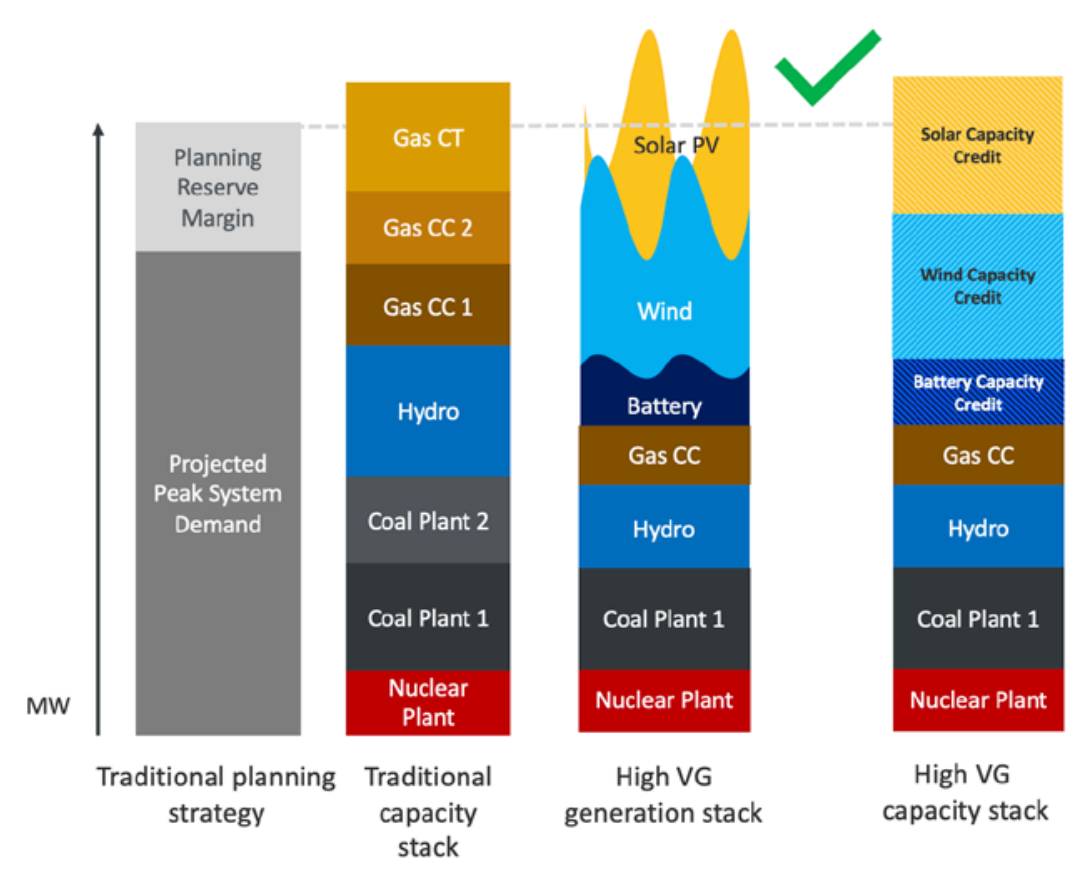

Figure 5: Illustrative firm capacity stacks for a traditional (thermal and hydro) and a high renewable energy power system (High VG). Source: (Nagarajan et al. 2021). with the existing assets. A two-part study with BSES Yamuna Power Ltd., a private Delhi utility, studied several concepts that will help utilities feel more comfortable with a high RE generation mix. From one perspective, NREL and BYPL explored the capacity credit of renewable energy resources that have been procured through the Solar Energy Corporation of India Limited (Nagarajan et al. 2021).

Figure 5 shows a simple illustration of how some portion of wind and solar generation can be considered firm capacity in BYPL's resource planning stages (i.e., reliably producing during certain periods), depending on the other characteristics of the system and on what periods are of concern." This study found that the 250 MW of wind resources being procured had an estimated capacity credit of 53\%. ${ }^{12}$ As demand in the region grows, and renewable energy plays a larger role in meeting that demand, considering the capacity contribution from renewable energy is critical to procuring the right amount of resources.

\footnotetext{
11 The primary driver of planning has historically been to plan for peak load periods. However, periods of concern or stress on the system are likely to change as renewable energy is added to the system and demand is considered a resource (MISO (Midcontinent Independent System Operator) 2021; W. Cole et al. 2020).

12 53\% applies to this specific set of resources and considering BYPL's existing assets. Capacity credit of a resource will likely decrease as more of a resource type is added to the generation mix (Haley 2019).
} 
While assigning capacity credits to renewable energy through portfolio-specific statistical approaches was a necessary first step, a generation mix with mostly renewable energy will need to progress its methods even further in the coming years. The Energy Systems Integration Group Resource Adequacy Task Force, a group that convenes power sector experts from around the globe to support grid transformation, recently published a set of considerations for redefining resource adequacy, attributing chronological operations (i.e., events in one period affect the ability to respond in another) and increasing impacts of weather as primary drivers of this proposed transformation (Redefining Resource Adequacy Task Force 2021). Without some advancements in considering renewable energy and other new technologies such as storage (see textbox) and demand response, more robustly in resource adequacy calculations, reaching very high levels of renewable energy will be more challenging and slow progress. Additionally, coordination and transparency will be an important component of

\section{Including Capacity from Storage Effects the System Needs}

Emerging low-cost energy storage from lithium-ion battery technologies has the potential to offset the need for new investments in fossil-fueled capacity. In India, for example, NREL's recent study showed that 4-hour duration storage devices could provide about $70 \mathrm{GW}$ of reliable capacity at 100\% capacity credit in 2030 (Chernyakhovskiy et al. 2021). The same study also demonstrated the potential risk of excluding the capacity contribution of energy storage in the planning process. If the capacity credit of storage is not considered, this scenario builds about $70 \mathrm{GW}$ of new fossil-fueled generation resources by 2030 to meet capacity adequacy requirements. As utilities consider the emerging role of energy storage in their planning process, including calculations for the capacity contribution of storage devices with different durations can help to fully capture their value to the system new frameworks, as resource adequacy has components that all stakeholders should consider.

\section{Managing Distributed Resource Growth}

In addition to DISCOMs reevaluating power procurement strategies, they are also navigating new technologies being added to their networks in the form of distributed energy resources, such as rooftop solar, battery energy storage systems, electric vehicles, and considering how demand can play a greater role in balancing. Economy-wide decarbonization efforts will only accelerate the need to adapt and to coordinate with other sectors.

A refrain from several of India's DISCOMs is the need for new models and tools to help evaluate this changing landscape. NREL has developed several tools and analysis frameworks in partnership with utilities around India that could be helpful for others in the region and beyond. EMeRGE, developed with input from Tamil Nadu Generation and Distribution Company, was built to help utilities improve the process for adding rooftop solar (Duwadi et al. 2021). By improving the visibility of potential future impacts to reliability and distribution asset health of rooftop solar, DISCOMs can more rapidly integrate these resources. The tool has two primary uses: (1) direct implementation into a DISCOM's rooftop solar application, and (2) assessing the impact of large-scale rooftop solar deployments.

Additionally, NREL worked with BSES Rajdhani Power Ltd. to assess the potential for demand to be utilized as a balancing resource in a demand-side management program (McKenna et al. 2021). To make this analysis repeatable, NREL developed a tool, EFFORT, to allow for time-of-use rates to be analyzed for demand flexibility. This work involved surveys to customers and detailed analysis of load characteristics for the BSES Rajdhani Power Ltd. territory. As demand is increasingly considered a potential resource by DISCOMs, planners, and operators, the impact of different tariff structures will be important to understand. This will be especially true as electrification of other sectors grows. But an approach involving surveys and other customer interactions is often not feasible or necessary when needing quick answers about changing or projected trends in demand. EVOLVE was developed with quick analysis in mind, allowing a utility (or other power sector researchers) to choose projected growth in rooftop solar, batteries, or electric vehicles and see the combined impact to the net load (Nagarajan et al. 2021).

While these tools and frameworks fill an important niche in planning for DISCOMs, to attain economy-wide decarbonization through widespread electrification and high renewable energy grids, many of these planning activities will need to be merged and expanded at a huge scale. A recent study with the city of Los Angeles (Section 1.2.3) provides some insight into the scale of these problems for a DISCOM. The study covered transmission and distribution system perspectives. From the distribution side, a large share of the effort was in creating detailed network models of the whole territory so that deployment of distributed solar, batteries, and electric vehicles could be mapped onto these networks without overly simplifying the localized impacts (Palmintier et al. 2021). A full representation of a territory's network may not be a necessary step in all studies of electrification and largescale renewable energy integration, but detailed network models will be integral to many questions regarding distributed energy resources and electrification, and building detailed network models may fall into the category of "no regrets data."

\section{State Grid Planners}

India's states have a leading role in managing the electric power grids. They plan, operate, and own transmission, generation, and the distribution assets 
Table 1. Modeling Tools to Help Utilities and Other Power Sector Researchers Assess the Impact of New and Emerging Technologies

\section{Advanced Planning \\ Tools for DISCOMs}

\begin{tabular}{|l|}
\hline EMERGE $^{\mathrm{a}}$ \\
\hline EFFORT $^{\mathrm{b}}$ \\
\hline
\end{tabular}

\section{EVOLVEc}

\section{Motivation for Developing Tool}

Assess the risk to a distribution network if a customer installs a rooftop solar system

Assess and optimize time-of-use rate structures for use in demandside management scheme

\section{Potential Application to Longer-Term Decarbonization Questions}

Assessing the impact to distribution assets and network reliability if city, state, or national policies for rooftop solar growth were promoted or undertaken

Assessing tariff designs of electrification measures such as electric vehicles and industrial processes

Linking outcomes of tariff design on impacts to broader resource planning (i.e., demand flexibility could be considered as a resource in planning and offset generation capacity or transmission/distribution asset needs)

Electrification policies and trends will likely develop (and continually change) in the coming years. Being able to quickly assess a policy target (or emerging trend) will help utilities prepare for changes and create projections of load for further use in planning. net load profile. Includes options for electric vehicle deployment, rooftop solar, and behind-the-meter batteries.

Quickly analyze the impact of

a. Fact Sheet: https://www.nrel.gov/docs/fy210sti/79996.pdf.

b. Access to open-source tool: https://github.com/nrel/effort

c. Access to open-source tool: https://github.nrel.gov/kduwadi/EVOLVE.

within the state. ${ }^{13}$ Given this wide spectrum of responsibility, they are in a critical position to influence how the sector can evolve. The most impactful near-term advancements for realizing a decarbonized power sector at the state level is to better integrate renewable energy into the generation and transmission planning process. Figure 6 shows a road map for advancements that could be taken up by states to better capture renewable energy characteristics within current planning practices. Some of the highest priority actions, such as engaging with stakeholders and increasing temporal resolution of planning analysis (e.g., understanding potential hourly balancing challenges), require relatively low effort and will help to improve understanding of new technologies such as wind, solar, and batteries. But if states are to help meet the needs of decarbonization by building high renewable energy grids (Section 1.2), they will need to reach the high-priority, high-effort activities of Figure $6 .{ }^{14}$ Advanced modeling (far right in figure), which can take years of investment and data aggregation to reap the benefits, will help state-level decision makers prepare for fast-approaching changes to how the power system needs to be planned and operated to achieve longer-term decarbonization targets. While states are busy integrating the highest priority topics, such as increasing the amount of scenarios considered in planning and navigating renewable energy capacity credit calculations, they can have parallel activities that build up advanced modeling capabilities for in-depth planning to inform power system decarbonization.

13 The ownership of assets varies between states, with private distribution companies in several states and private generation growing in many places in the country (MOP 2021). States also have regulatory authority over the power sector in the form of State Electricity Regulation Commissions.

14 Reaching the high-priority, high-effort activities implies that other activities (i.e., highest and higher) have already been adopted.

15 Other resources for learning about ReEDS: https://www.nrel.gov/analysis/reeds,

https://www.nrel.gov/international/india-renewable-energy-integration.html,

https://www.nrel.gov/docs/fy20osti/76153.pdf, https://www.nrel.gov/docs/fy21osti/80192.pdf,

https://www.nrel.gov/docs/fy21 osti/80190.pdf.

In addition to building the high renewable energy grids for India, states could also help to coordinate a better understanding of how electrification will change the power system requirements. For example, ensuring that state- and/or national-level policies, such as those in energy efficiency or vehicle electrification, are integrated with broader generation and transmission planning could have a large impact on what resources are needed on the power system. Integrating these various pieces, in part through

\section{An Open-Source Tool for India's Power System Planners}

ReEDS-India is an open-source capacity expansion model that can take into consideration policies, technological advancement, demand projections, etc., to optimize the investments in generation and transmission. Importantly, the model allows for changes to temporal and geographic resolution to ensure that variability from renewable energy and storage is considered in long-term planning. A recent application includes a study with the Indian state of Tamil Nadu to analyze several renewable energy policies and the impact of varying fuel prices (Rose et al. 2021). ${ }^{15}$ 


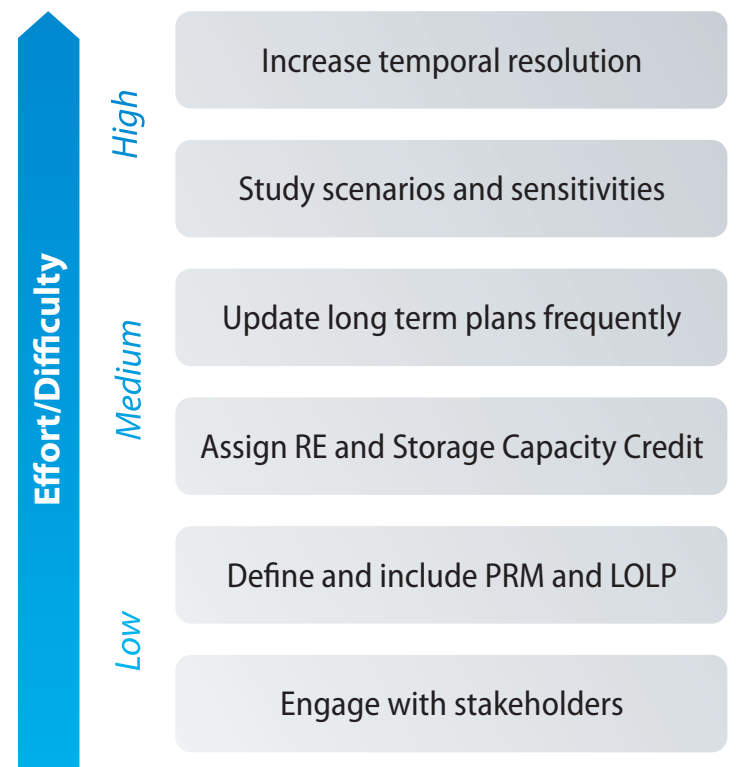

Highest
Increase coordination between states and region

Improve transmission planning by increasing geospatial resolution

Assess flexibility needs

Represent geographic RE diversity

Use multiple years of RE data
Coordinate planning across sectors

\section{Co-optimize generation} and transmission

Higher

High

\section{Priority}

Figure 6: Road map to advance power system planning activities in India's states. Source: (Joshi 2021)

stakeholder processes, will lead to more optimal outcomes. Additionally, the shared regulatory framework provided by the State Electricity Regulatory Commissions and the potential for a unified planning agency makes the states a suitable place for initial high-ambition studies on decarbonization.

\section{Central Power System Planners and Regulatory Agencies}

Central agencies, administered by the Ministry of Power, play an important role in India's power sector and, like the states, manage many aspects of the electricity grid, including generation, transmission, and system operations. CEA is at the center of planning for the country, with numerous public reports that form the basis of essentially all activities around power system planning in the country, including being key inputs to state and DISCOM planning exercises. In this sense, adding the two main components of decarbonization and electrification and high renewable energy grids to planning documents such as the Electric Power Survey, National Electricity Plans, and optimal generation mix reports would have far-reaching impact to states and DISCOMs considering these trends within their localized planning activities. And coordination with other central agencies, such as the Bureau of Energy Efficiency, Ministry of Housing and Urban Affairs, and others may help optimize benefits to sectors that will become increasingly linked in a decarbonized India.

The timing of power system transitions is also an important consideration. While electrification will likely bring down emissions from buildings, industry, and transport, if the grid is not supplied by zero-carbon sources, the emissions impacts will still be important to understand. Policymakers would benefit from knowledge about how these sector transitions may impact the overarching goal of decreased greenhouse gas emissions. Regardless, the earlier a low-carbon grid is reached, the easier other sectors can take advantage of emissions reductions by electrifying, so this should remain a priority for stakeholders as other sector transitions gain momentum.

\section{Conclusion}

The research pathways for decarbonization of the power sector in South Asia are building on a robust set of activities that are already underway. In many cases, the tools and models that are already developed could direct some of their questions toward decarbonization, such as increasing renewable energy deployment and creating simple scenarios of deep electrification. But in many cases, data and model development will need major new investments in time and effort. A good starting point is to create many years of weather data that can be synchronized with historical electricity load. This data is most valuable when the timescales match with those that power system operators consider, such as hourly or shorter, and the spatial granularity captures real weather phenomenon and power system network characteristics. Another potential step to prepare for decarbonization research and development is to start coordinating efforts with other sectors, such as buildings, industry, and transport, to create data that can be used in future electrification studies. 
This coordination could be especially useful in early-stage deployments of electrification so that the data collected is meaningful for power system studies. Good data can form the foundation of innumerable research activities by varying renewable energy and storage advances, energy efficiency, DER deployment, sector electrification, etc., that help to frame the best path forward and test solutions for efficient sector transformation.

DISCOMs, cities, and states may be the best organizations to undertake some of these research activities in the near-term, but coordination throughout the power sector will also be helpful at different stages.

\section{References}

Abhyankar, Nikit, Shruti M. Deorah, and Amol A. Phadke. 2021. "Least-Cost Pathway for India's Power System Investments through 2030."

Abhyankar, Nikit, Nihar Shah, Won Young Park, and Amol A. Phadke. 2017. "Accelerating Energy Efficiency Improvements in Room Air Conditioners in India: Potential, Costs-Benefits, and Policies." https://escholarship.org/uc/item/8710154k.

Anwar, Muhammad Bashar, Matteo Muratori, Paige Jadun, Elaine Hale, Brian Bush, Paul Denholm, Ookie $\mathrm{Ma}$, and Kara Podkaminer. 2022."Assessing the Value of Electric Vehicle Managed Charging: A Review of Methodologies and Results." Energy \& Environmental Science, 10.1039.D1EE02206G. https://doi. org/10.1039/D1EE02206G.

BBC News. 2021. "COP26: India PM Narendra Modi Pledges Net Zero by 2070," November 2, 2021, sec. India. https://www.bbc.com/news/ world-asia-india-59125143

BEE. 2020. "Compendium on DSM Measures by Distirbution Companies (DISCOMs)." Bureau of Energy Efficiency, Ministry of Power, Government of India. https://beeindia.gov.in/sites/default/files/ Compendium\%20on\%20DSM\%20measures\%20 undertaken\%20by\%20DISCOMs.pdf

Biswas, Tirtha, Deepak Yadav, and Ashish Guhan Baskar. 2020. "A Green Hydrogen Economy for India," 21.

Bloom, Aaron, Josh Novacheck, Gregory L Brinkman, James D Mccalley, Armando L. Figueroa-Acevedo, Ali Jahanbani Ardakani, Hussam Nosair, et al. 2021. "The Value of Increased HVDC Capacity Between Eastern and Western U.S. Grids: The Interconnections Seam Study." IEEE Transactions on Power Systems, 1-1. https://doi.org/10.1109/TPWRS.2021.3115092.

Bose, A. S., and S. Sarkar. 2019. "India's e-Reverse Auctions (2017-2018) for Allocating Renewable Energy Capacity: An Evaluation." Renewable and Sustainable Energy Reviews 112 (September): 762-74. https://doi.org/10.1016/j.rser.2019.06.025

Brinkman, Gregory, Dominique Bain, Grant Buster,
Caroline Draxl, Paritosh Das, Jonathan Ho, Eduardo Ibanez, et al. 2021. "The North American Renewable Integration Study (NARIS): A U.S. Perspective." NREL/ TP-6A20-79224, 1804701, Mainld:33450. https://doi. org/10.2172/1804701

CEA. 2017. "Brief on 19th Electric Power Survey." 2017. https://cea.nic.in/old/reports/others/planning/ pslf/summary_19th_eps.pdf.

2018. "National Electricity Plan - Volume I: Generation." New Delhi: Central Electricity Authority. http://www.cea.nic.in/reports/committee/nep/ nep_jan_2018.pdf.

2019a. "Long Term Electricity Demand Forecasting." Central Electricity Authority. https://cea.nic.in/ old/reports/others/planning/pslf/Long_Term_ Electricity_Demand_Forecasting_Report.pdf.

2019b. "Report on Nineteenth Electric Power Survey of India (Volume-III)." Central Electricity Authority. https://cea.nic.in/old/reports/others/planning/ pslf/19th_EPS_Mega\%20City_Part\%20II.pdf.

2019c. "Flexible Operation of Thermal Power Plant for Integration of Renewable Generation." https:// cea.nic.in/old/reports/others/thermal/trm/flexible_operation.pdf.

2020. "Report on Optimal Generation Capacity Mix for 2029-30." Government of India. https://cea.nic. in/old/reports/others/planning/irp/Optimal_mix report_2029-30_FINAL.pdf.

2021. "Renewable Energy Gneration Report March 2021." https://cea.nic.in/wp-content/uploads/ resd/2021/04/Broad_overview_March-1.pdf.

Chaturvedi, Vaibhav, and Ankur Malyan. 2021. "Implications of a Net-Zero Target for India's Sectoral Energy Transitions and Climate Policy," 24.

Chernyakhovskiy, Ilya, Mohit Joshi, David Palchak, and Amy Rose. 2021. "Energy Storage in South Asia: Understanding the Role of Grid-Connected Energy Storage in South Asia's Power Sector Transformation." NREL/TP--5C00-79915, 1811299, Mainld:39133. https://doi.org/10.2172/1811299.

Cochran, Jaquelin, Paul Denholm, and eds. 2021. "The Los Angeles 100\% Renewable Energy Study." Golden, CO: National Renewable Energy Laboratory.

Cole, Wesley, Daniel Greer, Jonathan Ho, and Robert Margolis. 2020. "Considerations for Maintaining Resource Adequacy of Electricity Systems with High Penetrations of PV and Storage." Applied Energy 279 (December): 115795. https://doi.org/10.1016/j. apenergy.2020.115795.

Cole, Wesley J., Danny Greer, Paul Denholm, A. Will Frazier, Scott Machen, Trieu Mai, Nina Vincent, and Samuel F. Baldwin. 2021. "Quantifying the Challenge of Reaching a 100\% Renewable Energy Power System for the United States." Joule 5 (7): 1732-48. https://doi.org/10.1016/j.joule.2021.05.011.

Davis Steven J., Lewis Nathan S., Shaner Matthew, Aggarwal Sonia, Arent Doug, Azevedo Inês L., Benson Sally M., et al. 2018. "Net-Zero Emissions Energy Systems." Science 360 (6396): eaas9793. https://doi.org/10.1126/science.aas9793.

Denholm, Paul, Douglas J. Arent, Samuel F. Baldwin, Daniel E. Bilello, Gregory L. Brinkman, Jaquelin M. Cochran, Wesley J. Cole, et al. 2021. "The Challenges of Achieving a 100\% Renewable Electricity System in the United States." Joule 5 (6): 1331-52. https://doi. org/10.1016/j.joule.2021.03.028

Duwadi, Kapil, Killian McKenna, Akshay Jain, Kajal Gaur, Adarsh Nagarajan, and David Palchak. 2021."An Analysis Framework for Distribution Network DER Integration in India: Distributed Solar in Tamil Nadu." Renewable Energy, 83.

Economic Times. 2021."Market-Based Economic Despatch Phase-l to Begin from April 1, 2022." The Economic Times, October 8, 2021. https:// economictimes.indiatimes.com/industry/energy/ power/market-based-economic-despatchphase-i-to-begin-from-april-1-2022/articleshow/86865106.cms?from $=$ mdr.

Eichman, J., K. Harrison, and M. Peters. 2014. "Novel Electrolyzer Applications: Providing More Than Just Hydrogen." NREL/TP-5400-61758, 1159377. https:// doi.org/10.2172/1159377

ENTSO-E. 2020. "Mid-Term Adequacy Forecast 2020: Appendix 2; Methodolody." Brussels, Belgium: ENTSO-E (European Network of Transmission System Operators for Electricity). https://eepublicdownloads.entsoe.eu/clean-documents/sdc-documents/MAF/2020/MAF_2020_Appendix_2 Methodology.pdf.

Guerra, Omar J., Joshua Eichman, Jennifer Kurtz, and Bri-Mathias Hodge. 2019. "Cost Competitiveness of Electrolytic Hydrogen." Joule 3 (10): 2425-43. https:// doi.org/10.1016/j.joule.2019.07.006

Hale, Elaine, Anthony Fontanini, Eric Wilson, Henry Horsey, Andrew Parker, Matteo Muratori, Colin McMillan, et al. 2021. "Chapter 3. Electricity Demand Projections," 251.

Hale, Elaine, Henry Horsey, Brandon Johnson, Matteo Muratori, Eric Wilson, Brennan Borlaug, Craig Christensen, et al. 2018. "The Demand-Side Grid (Dsgrid) Model Documentation." NREL/TP-6A2071492, 1465659. https://doi.org/10.2172/1465659.

Haley, Chris. 2019." Solar and Wind ELCC Accreditation." Southwest Power Pool, Inc. https:// www.spp.org/documents/61025/elcc\%20 solar\%20and\%20wind\%20accreditation.pdf.

He, Guannan, Dharik S. Mallapragada, Abhishek Bose, Clara F. Heuberger-Austin, and Emre Gençer. 2021. "Sector Coupling via Hydrogen to Lower the Cost of Energy System Decarbonization." Energy \& Environmental Science 14 (9): 4635-46. https://doi. org/10.1039/D1EE00627D

IEA. 2016. "Snapshot of Global PV Markets - 2015." https://iea-pvps.org/wp-content/uploads/2020/01/ IEA-PVPS_-_A_Snapshot_of_Global_PV_-_19922015__Final_2_02.pdf.

2021. "Snapshot of Global PV Markets - 2020," 21.

2021. "Renewable Electricity Growth Is Accelerating Faster than Ever Worldwide, Supporting the Emergence of the New Global Energy Economy - News." IEA, December 2021. https://www.iea. org/news/renewable-electricity-growth-is-accelerating-faster-than-ever-worldwide-supporting-the-emergence-of-the-new-global-energy-economy.

Joshi, Mohit. 2021."80191.Pdf." 2021. https://www. nrel.gov/docs/fy21osti/80191.pdf.

Joshi, Mohit, David Hurlbut, and David Palchak. 2020. "Simulation of Cross-Border Renewable Energy Trading in South Asia." NREL/ 
PR-6A20-77029, 1659792, Mainld:24992. https://doi. org/10.2172/1659792.

Mai, Trieu T., Paige Jadun, Jeffrey S. Logan, Colin A. McMillan, Matteo Muratori, Daniel C. Steinberg, Laura J. Vimmerstedt, Benjamin Haley, Ryan Jones, and Brent Nelson. 2018. "Electrification Futures Study: Scenarios of Electric Technology Adoption and Power Consumption for the United States." NREL/TP--6A20-71500, 1459351. https://doi. org/10.2172/1459351

McBennett, Brendan, Amy Rose, David Hurlbut, David Palchak, and Jaquelin Cochran. 2019. "CrossBorder Energy Trade between Nepal and India: Assessment of Trading Opportunities."Technical Report NREL/TP-6A20-72066. Golden, CO: National Renewable Energy Laboratory. https://www.nrel. gov/docs/fy19osti/72066.pdf

McKenna, Killian, Kapil Duwadi, Shibani Ghosh, Adarsh Nagarajan, David Palchak, Abhishek Ranjan, Avinash Kumar, Jayanta Bora, and Krushna Kaant Gupta. 2021. "Preparing Distribution Utilities for the Future - Unlocking Demand-Side Management Potential: A Novel Analytical Framework." NREL/ TP-5C00-79375, 1811649, Mainld:33601. https://doi org/10.2172/1811649.

MISO (Midcontinent Independent System Operator) 2021. "MISO's Renewable Integration Impact Assessment, Sumary Report." Carmel, IN. https:// cdn.misoenergy.org/RIIA\%20Summary\%20 Report520051.pdf.

Modi, Narendra. 2021. "National Statement by Prime Minister Shri Narendra Modi at COP26 Summit in Glasgow." 2021. pib.gov.in/Pressreleaseshare. aspx?PRID=1768712.

MOP. 2021. "Power Sector at a Glance ALL INDIA | Government of India | Ministry of Power." 2021. https://powermin.gov.in/en/content/ power-sector-glance-all-india.

Nagarajan, Adarsh, Shibani Ghosh, Kapil Duwadi, Marty Schwarz, Richard Bryce, Ilya Chernyakhovskiy, David Palchak, et al. 2021. "Preparing Distribution Utilities for the Future Evolving Customer Consumption in Renewable Rich Grids: A Novel Analytical Framework." NREL/
TP-6A20-79069, 1779220, Mainld:32986. https://doi. org/10.2172/1779220

Novacheck, Joshua, Justin Sharp, Marty Schwarz, Paul Donohoo-Vallett, Zach Tzavvelis, Grant Buster, and Michael Rossol. 2021. "The Evolving Role of Extreme Weather Events in the U.S. Power System with High Levels of Variable Renewable Energy." NREL/TP-6A20-78394, 1837959, Mainld:32311. https://doi.org/10.2172/1837959.

Palchak, David, Jaquelin Cochran, Ali Ehlen, Brendan McBennett, Michael Milligan, Ilya Chernyakhovskiy, Ranjit Deshmukh, et al. 2017. "Greening the Grid: Pathways to Integrate 175 Gigawatts of Renewable Energy into India's Electric Grid, Vol. I-National Study." National Renewable energy Laboratory, USAID and Ministry of Power. https://www.nrel.gov/ docs/fy17osti/68530.pdf.

Palmintier, Bryan, Meghan Mooney, Kelsey Horowitz, Sherin Abraham, Tarek Elgindy, Kwami Sedzro, Ben Sigrin, Jane Lockshin, Brady Cowiestoll, and Paul Denholm. 2021. "Chapter 7. Distribution System Analysis," 117

Prasad, Nithin Thomas. 2020. "ReNew Power Wins SECl's 400 MW Round-The-Clock Renewable Tender at 2.90/KWh." Mercom India (blog). May 8, 2020. https://mercomindia.com/ renew-power-seci-round-clock-renewable-tender/

Redefining Resource Adequacy Task Force. 2021 "Redefining Resource Adequacy for Modern Power Systems." Reston, VA: Energy Systems Integration Group. https://www.esig.energy/reports-briefs.

Rose, Amy, Ilya Chernyakhovskiy, David Palchak, Marty Schwarz, Sam Koebrich, and Mohit Joshi. 2021. "Pathways for Tamil Nadu's Electric Power Sector: 2020 - 2030." NREL/TP--6A20-78266, 1760656, Mainld:32183. https://doi.org/10.2172/1760656.

Rose, Amy, Ilya Chernyakhovskiy, Joseph Palchak, Samuel Koebrich, and Mohit Joshi. 2020. "Least-Cost Pathways for India's Electric Power Sector." NREL/ TP-6A20-76153, 1659816, Mainld:6155. https://doi. org/10.2172/1659816

Rose, Amy, Brendan McBennett, Joseph D. Palchak, Jaquelin M. Cochran, H.M. Wijekoon, Buddhika
Samarasekara, and Randika Wijekoon. 2018 "Cross-Border Electricity Trade between India and Sri Lanka: Impact on Power System Operations." NREL/TP--6A20-71983, 1485773. https://doi. org/10.2172/1485773

Soonee, S K, K V S Baba, S R Narasimhan, S S Barpanda, S C Saxena, Mohit Joshi, and KVN Pawan Kumar. n.d. 2017"Initiatives Taken for Facilitating Large Scale Integration of Renewable Energy in India," 9

Spencer, Thomas. 2020. "Bending The Curve: 2025 Forecasts for Electricity Demand by Sector and State in the Light of the COVID-19 EPIDEMIC."The Energy And Resources Institute (TERI). https://www.teriin org/sites/default/files/2020-07/Bending-theCurve_Report.pdf.

Spencer, Thomas, and Aayushi Awasthy. 2019. "Analysing and Projecting Indian Electricity Demand to 2030." New Delhi: The Energy and Resources Institute (TERI). https://www.teriin. org/sites/default/files/2019-02/Analysing\%20 and $\% 20$ Projecting $\% 20$ Indian $\% 20$ Electricity $\% 20$ Demand\%20to\%202030.pdf.

Tata Power. 2021. "India's First Ever Large Scale 50MWh Battery Energy Storage System Co-Located with 50MW Solar PV Plant, EPC Project of INR 386Cr, at Leh Awarded to Tata Power Solar." August 2021. https://www.tatapower.com/media/ PressReleaseDetails/1875/indias-first-ever-largescale-50mwh-battery-energy-storage-system-colocated-with-50mw-solar-pv-plant.

\section{Written by David Palchak, Ilya Chernyakhovskiy, Mohit Joshi — National Renewable Energy Laboratory}

\section{Monali Hazra}

U.S. Agency for International Development Email: mhazra@usaid.gov

\section{David Palchak}

National Renewable Energy Laboratory

Email: david.palchak@nrel.gov

Meredydd Evans

Pacific Northwest National Laboratory

Email:m.evans@pnnl.gov

\section{Shruti Deorah}

Lawrence Berkeley National Laboratory

Email: smdeorah@lbl.gov

NREL/TP-6A40-81944 | January 2022
The South Asia Group for Energy (SAGE) is a consortium comprising USAID, the U.S. Department of Energy and three national laboratories: the Lawrence Berkeley National Laboratory (LBNL), the National Renewable Energy Laboratory (NREL), and the Pacific Northwest National Laboratory (PNNL). The consortium represents excellence in research and international development in the energy sector to advance the Asia Enhancing Development and Growth through Energy (Asia EDGE) priorities in the South Asia region.

\section{USAID MNREL}
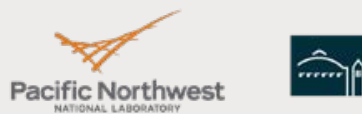

BERKELEY LAB

This work was authored, in part, by the National Renewable Energy Laboratory (NREL), operated by Alliance for Sustainable Energy, LLC, for the U.S. Department of Energy (DOE) under Contract No. DEAC36-08GO28308. Funding provided by the United States Agency for International Development (USAID) under Contract No. AID-386-T-16-00002 The views expressed in this report do not necessarily represent the views of the DOE or the U.S. Government, or any agency thereof, including USAID. 